\title{
Representasi Gay Melalui Penggunaan Warna \\ (Analisis Semiotika Video Klip Color Mnek)
}

\author{
Ladya Lieggiana Agnes, Riris Loisa \\ ladya.915150123@stu.untar.ac.id,ririsl@untar.ac.id
}

Fakultas Ilmu Komunikasi Universitas Tarumanagara

\begin{abstract}
Video clips are media that easily influence or channel ideological messages to the public. Videos are often used as a tool to construct issues such as Lesbian, Gay, Bisexual, and Transgender (LGBT) issues. This study discusses gay representation through the use of colors in the "Color" MNEK video clip. This research uses several theories, including representation theory, video clips, color, gender, culture, semiotics. This study uses descriptive qualitative research methods to obtain in-depth discussion of the object under study, using Jacques Derrida's Semiotic analysis which is a method of dismantling a rational thought. To conduct this research, the author screenshooted some of the Color MNEK video clip scenes that show gay representation through the use of colors. It can be concluded that color represents gay through meaning that is intentionally built by gays based on the nature of the colors namely bright pink representing sexuality, red represents life, orange healing, yellow miracle, natural green, turquoise miracle, indigo serenity and purple spirit. These colors are adopted by gays to show that the existence of gays is a complement that shows the diversity in the social community.
\end{abstract}

Keywords: representation, color, gay, culture, Semiotics, Color MNEK.

\begin{abstract}
Abstrak
Video klip merupakan media yang dengan mudah memberi pengaruh atau menyalurkan pesanpesan ideologis kepada khalayak. Video sering digunakan sebagai alat untuk mengkonstruksi isu-isu salah satunya isu mengenai Lesbian, Gay, Biseksual, dan Transgender (LGBT). Penelitian ini membahas mengenai representasi gay melalui penggunaan warna dalam video klip "Color" MNEK. Penelitian ini menggunakan beberapa teori, diantaranya teori representasi, video klip, warna, gender, budaya. Penelitian ini menggunakan metode penelitian kualitatif deskriptif untuk mendapatkan pembahasan yang mendalam mengenai objek yang diteliti, dengan menggunakan analisis Semiotika Jacques Derrida yang merupakan metode pembongkaran suatu pemikiran rasional. Dalam melakukan penelitian ini, penulis melakukan screenshoot pada beberapa scene video klip Color MNEK yang menunjukkan representasi gay lewat penggunaan warna. Dapat ditarik kesimpulan bahwa warna merepresentasikan kaum gay melalui makna yang sengaja dibangun oleh kaum gay berdasarkan sifat warna tersebut yaitu merah muda terang mewakili seksualitas, merah mewakili kehidupan, orange penyembuhan, kuning keajaiban, hijau alam, turquoise keajaiban, indigo ketenangan dan ungu semangat. Warna-warna tersebut diadopsi oleh kaum gay untuk menunjukkan bahwa keberadaan kaum gay menjadi pelengkap yang menunjukkan adanya keberagaman dalam sosial masyarakat.
\end{abstract}

Kata Kunci: representasi, warna, gay, budaya, Semiotika, Color MNEK. 


\section{Pendahuluan}

Rekaman dam pemutaran musik dimulai sekitar tahun 1880 dan rekaman cukup cepat menyebar, berdasarkan daya tarik yang luas dari lagu dan melodi popular (McQuail,2012). Awalnya lagu hanya menjadi sebuah sarana hiburan dan hobi untuk didengar. Sifatnya yang ringan dan dapat didengar dimana saja, kapan saja membuat musik menjadi media yang diminati banyak kalangan. Namun kini lagu menjadi sebuah sarana komunikasi ekspresif di mana didalamnya seorang penyanyi mampu memberikan suatu bentuk ekspresi diri dengan tujuan untuk memotivasi ataupun membentuk suatu persepsi yang hendak dibagikan ke pendengar. Selain itu, lagu juga dapat dijadikan sebagai sebuah ajakan dan membentuk suatu pergerakan. Musik juga memiliki peranan dalam pergerakan nasionalis independen, misalnya lagu protes dan nasionalisme. Musik menjadi elemen yang memungkinkan masyarakat menyatu, mengekspresikan aspirasi (McQuail, 2012).

Dalam sebuah video klip selain dihadirkan gambar-gambar yang mendukung lirik yang ada. Video klip juga merupakan suatu rangkaian cerita yang mengisahkan hal-hal yang telah ada atau yang diharapkan ada di kehidupan sosial yang dirangkai secara indah. Hal ini dikarenakan musik biasanya dibuat berdasarkan bentuk perwujudan dari imajinasi si penyanyi atau kehidupan sosial seseorang, atau suatu hal yang menjadi cita-cita yang ingin dwujudkan dalam kehidupannya. Dengan demikian, cerita dalam video klip dibuat seolah nyata dan berekspresi, sehingga mampu menarik perhatian dari masyarakat luas.

Tokoh-tokoh dalam rangkaian cerita video klip dibuat dan ditata menjadi sebuah sosok yang nyata yang seolah merepresetasikan sebuah kehidupan di dunia sosial. Genre dalam musik memiliki banyak aliran misalnya pop, rock, klasik, dan sebagainya. Lagu juga dibuat berdasarkan banyak perasaan, mulai dari bahagia, sedih, bangga, kecewa. Dari sekian banyak cerita yang mampu dijadikan sebuah music, tema percintaaan menjadi paling banyak memiliki daya pikat.

Salah satu lagu percintaan yang banyak didengar adalah lagu "Color" yang dinyanyikan oleh MNEK. Uzoechi Osisioma Emenike atau yang dikenal dengan nama MNEK adalah seorang produser, penulis lagu, sekaligus penyanyi inggris berdarah Nigeria. Pada tahun 2018 MNEK hadir album pertamanya dengan lagu yang berjudul "Color" yang menjadi lagu debut pada album "Language". Lagu "Color" yang berarti warna, MNEK meceritakan tentang keindahan cinta yang membuat hidup menjadi berwarna.

Dilansir dari www.billboard.com lagu ini pernah menjadi nominasi dalam grammy awards kategori lagu LGBTQ, dan menjadi lagu yang ditunggu-tunggu untuk dirilis pada juni 2018. Semenjak di posting dalam official chanel youtube MNEK pada juni 2018, lagu ini telah ditonton lebih dari 21 juta viewers.

Selain itu yang menjadi menarik dalam lagu ini adalah cerita percintaan yang disampaikan oleh MNEK mengisahkan hubungan laki-laki sejenis atau yang biasa disebut dengan gay dalam bentuk yang lebih "coming out". Banyak lagu yang mengisahkan mengenai hubungan gay, namun biasanya cerita tersebut dibuat menjadi lebih tersirat melalui adegan-adegan atau lirik yang lebih indah, Bahkan jika seorang pendengar tidak mengenali latar belakang dari penyanyinya, sulit untuk menyadari maksud dari cerita yang dikisahkan dalam lagu tersebut.

Selain itu juga beberapa tanda-tanda terkait hubungan percintaan sejenis juga dilambangkan dengan sebuah simbol yang tidak lazim digunakan dalam kehidupan masyarakat. Kebutuhan pokok manusia menurut Susanne K. Langer adalah kebutuhan 
simbolisasi atau penggunaan lambang. Lambang atau simbol adalah sesuatu yang digunakan untuk menunjuk sesuatu lainnya, berdasarkan kesepakatan sekelompok orang. Lambang meliputi kata-kata (pesan verbal), perilaku (non-verbal) dan objek yang maknanya disepakati bersama (Deddy, 2007). Salah satu tanda yang digunakan untuk menunjukkan suatu makna gay terdapat dalam video klip lagu Troye Sivan yang berjudul "Youth", ia menggunakan salah satu tanda yang tidak lazim yaitu menyilangkan jari telunjuk dengan jari tengah yang mengartikan suatu hubungan dalam percintaan sejenis. Tanda tanda seperti inilah yang biasanya digunakan dalam sebuah video klip LGBTQ, tidak semua lapisan masyarakat memahami dan mengerti makna dari tanda tersebut.

Dalam lagu "Color" yang dinyanyikan oleh MNEK terdapat warna-warna yang dianggap merepresentasikan gay yang akan dikaji dan diteliti lebih dalam lagi. Yang menjadi fokus permasalahan dalam penelitian ini adalah bagaimana representasi gay melalui penggunaan warna pada video klip lagu "Color" oleh MNEK. Dengan tujuan penelitian dapat mengetahui representasi gay melalui penggunaan warna dalam video klip color MNEK. Penelitian ini diharapkan mampu memberikan pengetahuan secara akademis dan praktis.

\section{Metode Penelitian}

Penelitian yang dilakukan berupa penelitian kualitatif bertujuan untuk menjelaskan dan menggali pemahaman mengenai makna yang terjadi pada individu atau suatu kelompok. Brogan dan Taylor menyatakan bahwa metode penelitian kualitatif adalah sebuah prosedur penelitian yang menghasilkan data deskriptif berupa rangkaian kata tertulis ataupun lisan dari objek yang diamati (dalam Moleong 2013). Penelitian kualitatif adalah penelitian yang bersifat intepretatif, penafsiran, sehingga melibatkan beberapa metode dalam mengolah sebuah masalah yang hendak diteliti.

Dalam penelitian ini, peneliti menggunakan strategi penelitian studi kasus. Penelitian studi kasus adalah penelitian yang meneliti fenomena kontemporer secara utuh dan menyeluruh pada kondisi sebenarnya. Pada penelitian ini, subjek yang digunakan oleh peneliti adalah representasi gay. Sedangkan objek penelitian penggunaan warna. Data yang dikumpulkan terbagi menjadi dua, yaitu data primer berupa observasi, dokumentasi dan wawancara terhadap empat narasumber, dan data sekunder berupa studi pustaka. Studi pustaka adalah tekhnik pengumpulan data dengan cara mencari data dan informasi melalui membaca buku-buku, referensi, dan bahan lainnya yang tersedia (Ruslan, 2008). Selain itu beberapa skripsi dan jurnal komunikasi terkait juga dijadikan sebagai referensi. Dalam penelitian ini penulis menggunakan analisis semiotika model Derrida.

Dekonstruksi ini merupakan sebuah alternatif untuk menghilangkan segala keterbatasan penafsiran atau penyimpulan yang baku. Konsep ini membongkar produk pemikiran rasional yang mempercayai kemurnian realitas. Menurut Turiman 2015 dalam penelitian terdahulu dekonstruksi bisa diartikan sebagai pembongkaran, namun bukanlah pembongkaran atau penghancuran yang berakhir kekosongan. Dekonstruksi juga bukan metode tafsir yang dilengkapi dengan perangkat-perangkat konseptual yang serba argumentatif dan koheren. Bahkan dekonstruksi justru anti metode, anti argumentasi, dan anti koherensi, karena pandangan ini berbau ilmiah dan positivistik. Dekonstruksi membuka luas pemaknaan sebuah tanda, sehingga makna-makna dan ideologi baru mengalir tanpa henti dari tanda tersebut. Munculnya ideologi baru bersifat menyingkirkan (menghancurkan atau mendestruksi) makna sebelumnya, 
terus-menerus tanpa henti hingga menghasilkan puing-puing makna dan ideologi yang tak terbatas. Dekonstruksi memungkinkan sebuah tanda untuk ditafsirkan seperti apa saja, tidak ada batasan dalam pemaknaan.

\section{Hasil Temuan dan Diskusi}

Setelah melakukan observasi di lapangan dan melakukan wawancara dengan informan, penulis menemukan beberapa hal menarik selama menjalani wawancara dengan narasumber:

Komunitas Sisterhood dan klasifikasi gay

Sisterhood adalah komunitas kecil atau komunitas cabang dari komunitas-komunitas LGBT besar. Dalam komunitas sisterhood, para kaum gay ini tidak terbagi dalam klasifikasi-klasifikasi tertentu. Namun dalam kenyataanya beberapa gay sendirilah yang mengelompokkan diri mereka kedalam golongan tertentu, misalnya ada golongan gay yang aktif dominan dalam kehidupan sehari-hari, ada yang cukup dominan, ada juga yang benar-benar pasif sama sekali. Ada pula gay yang mengklasifikasikan dirinya berdasarkan role sex yang mereka perankan, misalnya yang menjadi wanitanya disebut bottom dan yang menjadi laki-lakinya adalah top. Namun hal ini tidak selamanya berlaku, terkadang gay yang berperan oimenjadi top dapat juga menjadi bottom dan sebaliknya.

Adegan dalam Video klip sebagai penyampaian pesan dan Ideologi gay

Hal menjadi bagian dari perhatian penulis adalah ketika video yang merupakan salah satu media massa awalnya berfungsi sebagai sarana hiburan kini mampu menjadi salah satu ajang penyampain pesan terselubung. Menurut Judith pemilik media juga tidak menyia-nyiakan keberadaan komunitas LGBT untuk juga menjual ideologi mereka. Setelah melakukan wawancara dengan beberapa narasuber, dapat ditarik kesimpulan bahwa pada video klip "Color" MNEK mengandung beberapa adegan yang digunakan sebagai media untuk menyampaikan pesan ideologi terkait gay, yang didukung dari lirik dan gambar-gambar yang ada pada beberapa scene.

Gambar 1. Scene Video Klip Color Mnek

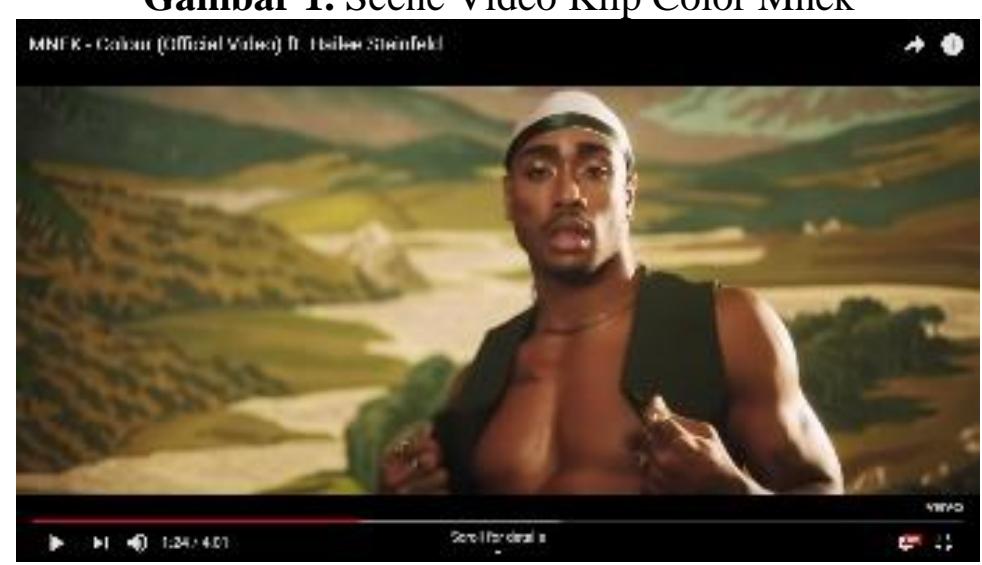

Sumber:https://www.youtube.com/watch?v=ZMmwDy-27AM (2019) 
Gambar 2. Scene Video Klip Color Mnek

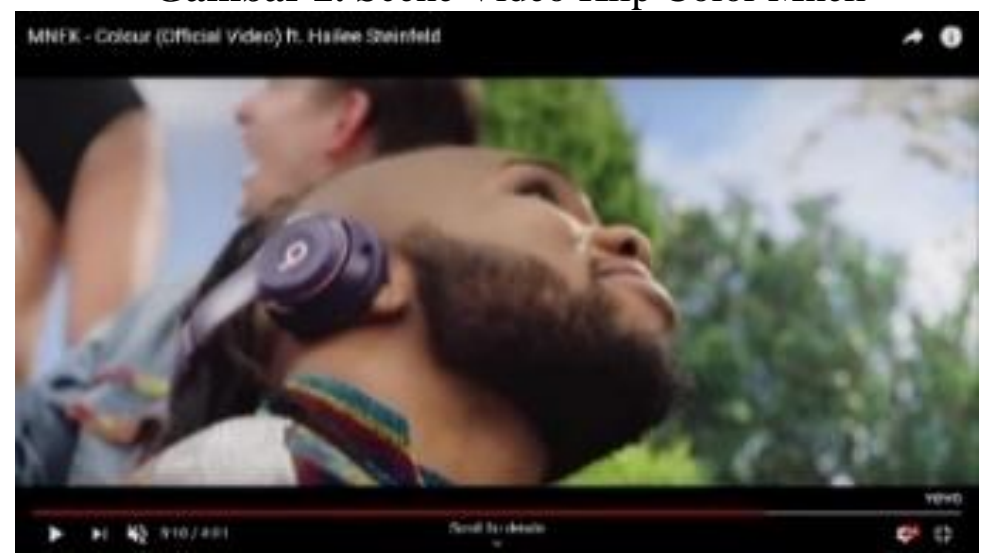

Sumber: https://www.youtube.com/watch?v=ZMmwDy-27AM (2019)

Pro-Kontra warna sebagai perwakilan gay

Menurut Go dalam jurnalnya representasi adalah bagaimana seseorang, satu kelompok, gagasan, pendapat, realitas atau objek tertentu ditampilkan dalam sebuah teks. Menurut Hartley 2010 dalam Paramita, representasi berarti menggunakan bahasa untuk menyatakan sesuatu secara bermakna atau mempresentasikan kepada orang lain. Dalam representasi sangat mungkin terjadi misrepresentasi yang artinya ketidakbenaran penggambaran atau kesalahan penggambaran. Salah satu bentuk misrepresentasi adalah marjinalisasi. Marjinalisasi adalah penggambaran yang buruk kepada pihak atau kelompok lain. Setelah melakukan wawancara dengan beberapa narasumber, penulis menemukan sebuah perdebatan pro-kontra mengenai warna sebagai bentuk perwakilan dari gay. Menurut beberapa informan yang mengakui dirinya sebagai gay menyatakan merasa direpresentasikan oleh warnawarna yang ada dalam video klip tersebut. Sementara menurut hasil wawancara dengan narasumber yang menjadi narasumber kunci menyatakan warna tidak menjadi perwakilan dari suatu objek.

Gambar 3. Scene Video Klip Color Mnek

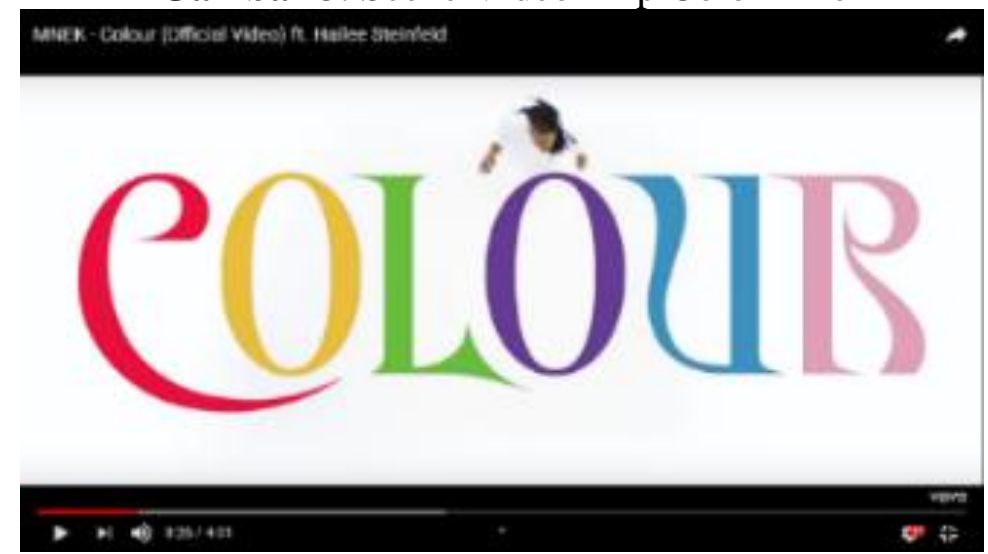

Sumber: https://www.youtube.com/watch?v=ZMmwDy-27AM (2019)

Independenitas Warna

Setelah melakukan wawancara dengan salah satu narasumber, beliau menjelaskan tentang warna yang sebenarnya tidak mencerminkan atau mengklasifikasikan sesuatu. Beliau menegaskan bawa setiap warna memang 
memiliki makna khusus, seperti merah yang melambangkan kekuatan, energi, nafsu, agresi seperti yang diungkapkan oleh Nugroho (2017) dalam buku Teori Pengenalan Warna. Namun hanya sebatas sifat dari warna tersebut saja.

Perbedaan gestur gay wilayah Timur dan Barat.

Setelah melakukan wawancara penulis menemukan fakta baru bahwa gestur tubuh yang diciptakan dari kaum gay di budaya barat dan budaya timur berbeda. Fakta bahwa gay dalam budaya barat lebih terbuka dalam mengekspresikan jati dirinya, sementara di Indonesia yang masih menganut budaya timur dengan nilai-nilai ketaatan, kesopanan, dan kesantunan lebih tergolong sukar untuk mengekspresikan diri. Meskipun ada beberapa gay yang sudah mulai terbuka, namun masih banyak juga gay yang cenderung menutupi jati dirinya.

Kritik terhadap budaya patriarki

Menurut Marla Mies dalam Omara dalam jurnalnya budaya patriarki ini dianggap sebagai budaya nilai yang menempatkan laki-laki pada posisi yang lebih tinggi daripada perempuan, dan budaya ini merembes pada segala bentuk lapisan masyarakat. Dalam video klip ini sosok MNEK sebagai laki-laki feminim menunjukkan dirinya mampu menjadi raja dan pusat perhatian, dimana sosok lakilaki dan raja dalam dunia nyata digambarkan sebagai sosok yang maskulin namun disini laki-laki feminim ternyata mampu menjadi menempatkan diri pada posisi yang biasanya diisi oleh laki-laki maskulin. Selain itu menurut Mukarom dalam jurnalnya perempuan memiliki hak yang daa untuk berpartisipasi dalam berbagai bidang kehidupan. Termaksud menempati posisi tertinggi, yang dalam video klip ini adalah seorang ratu. Jika diperhatikan dalam video klip ini sosok Hailee dianggap seperti seorang ratu yang berdiri menggenakan mahkota pada kepalanya.

Gambar 4. Scene Video Klip Color Mnek

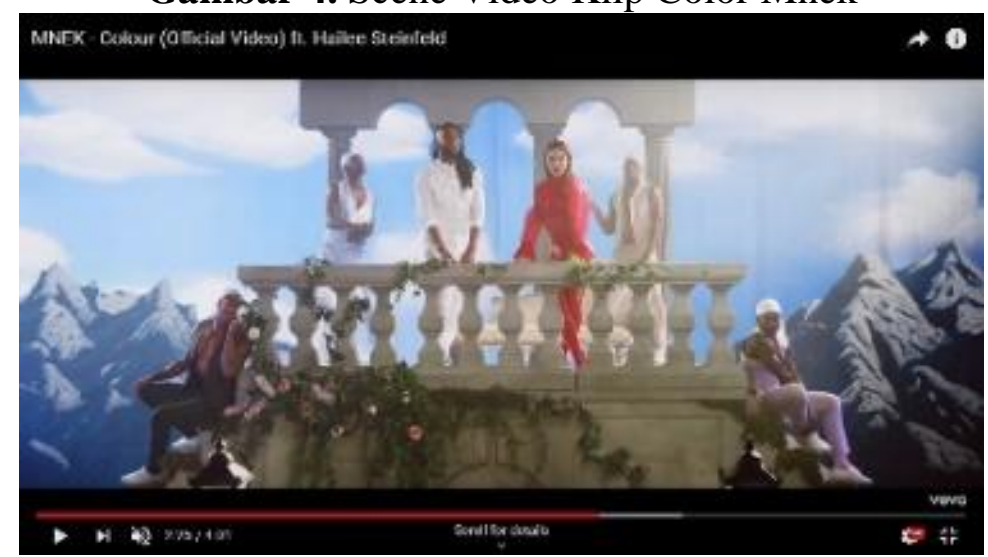

Sumber: https://www.youtube.com/watch?v=ZMmwDy-27AM (2019)

Upaya perdamaian LGBT dengan Media

Dalam teori konstruksi realitas mengkoreksi substansi kelemahan dan melengkapi konstruksi sosial atas realitas, dengan menempatkan seluruh kelebihan media massa dan efek media pada keunggulan. Sehingga dapat dikatakan media memiliki power lebih dalam upaya menyebarkan informasi atau ideologi maupun paham sosial. Pada scene ini menunjukkan kritikan sekaligus pengharapan LGBT kepada media. Sebuah cerita yang terangkai dari adegan-adengan dalam video klip mengandung unsur-unsur yang sudah ada dimasyarakat. Hal ini dikarenakan biasanya 
cerita dalam video klip merupakan cerminan dari realitas sebuah kelompok ataupun seseorang, ataupun sebuah keinginan yang ingin dicapai oleh kelompok. Sehingga dirangkai sedemikian lebih indah agar mudah diterima oleh masyarakat luas

Gambar 5. Scene Video Klip Color Mnek

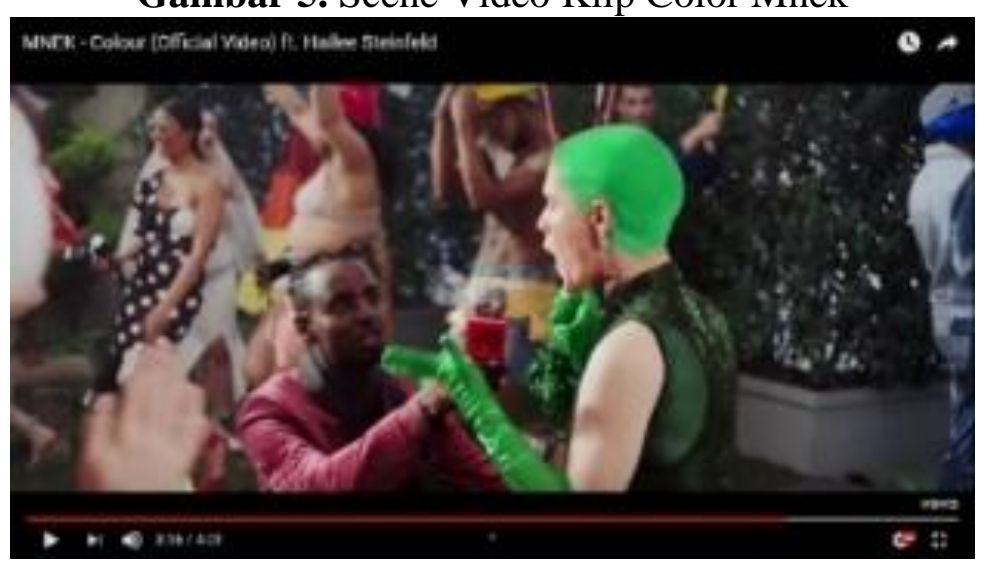

Sumber: https://www.youtube.com/watch?v=ZMmwDy-27AM (2019)

\section{Simpulan}

Berdasarkan hasil analisis data yang telah peneliti lakukan, maka dapat disimpulkan bahwa kepribadian gay dalam video Color MNEK tergambar dari warnawarna yang dipakai misalnya yang tergolong gay feminim mengenakan warna yang lebih soft sedangkan yang sifatnya lebih maskulin digambarkan dengan warna-warna yang lebih berani.

Gambar 6. Scene Video Klip Color Mnek

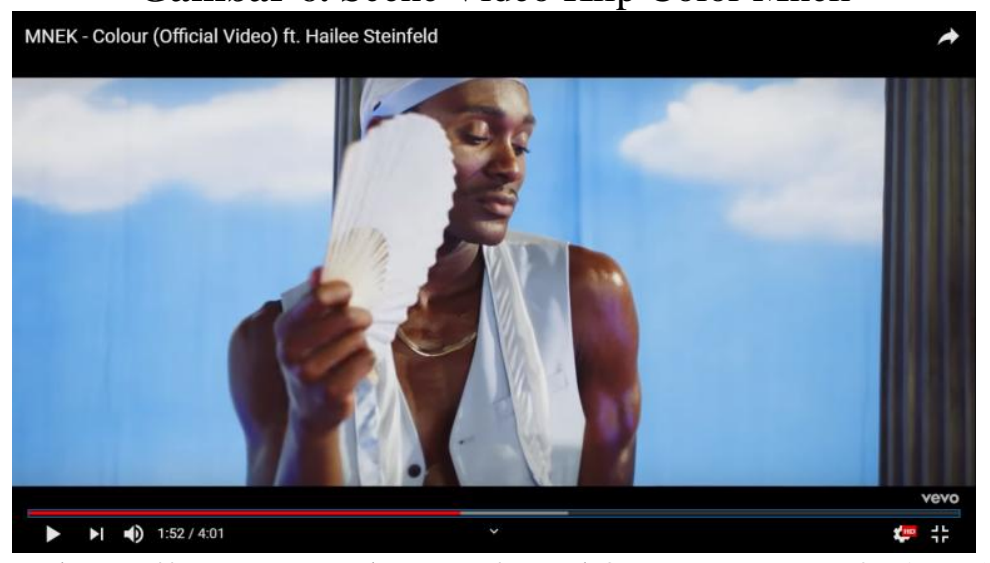

Sumber: https://www.youtube.com/watch?v=ZMmwDy-27AM (2019) 
Gambar 7. Scene Video Klip Color Mnek

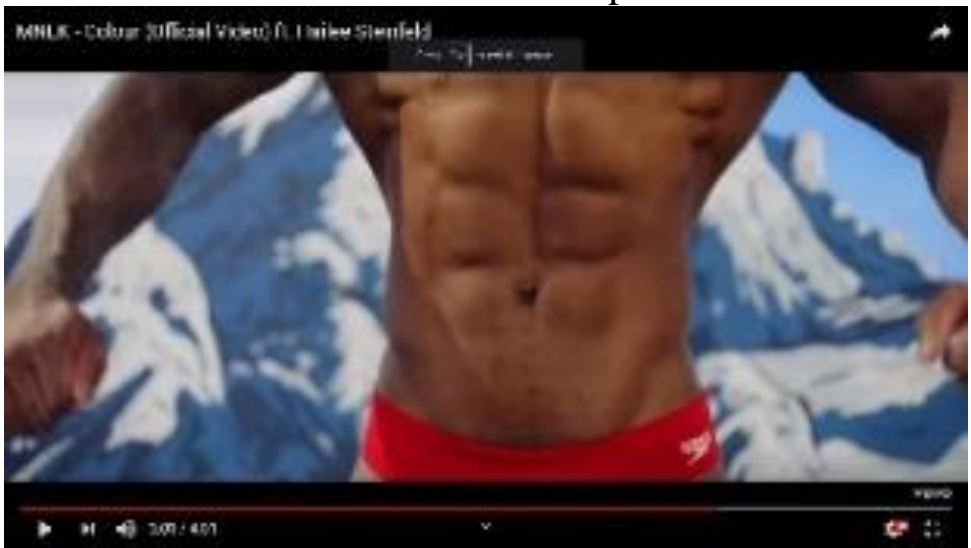

Sumber: https://www.youtube.com/watch?v=ZMmwDy-27AM (2019)

Sedangkan sosok gay dalam video tersebut tidak direpresentasikan oleh warna yang ada. Warna-warna dalam video klip tersebut lebih sebagai diom yang merunjuk pada pernyataan keberagaman. Hal ini dikarenakan warna tidak melambangkan suatu hal apapun, salah satunya melambangkan LGBT, warna memiliki hakikat yang indepent. Warna memang memiliki arti dan makna khusus namun warna-warna tersebut tidak melambangkan suatu bentuk apapun. Namun terkadang manusialah yang mengadopsi makna dari warna-warna tersebut dan bangun makna baru berdasarkan sifat warna tersebut.

Melalui metode semiotika dekonstruksi penulis menemukan fakta bahwa selain memberikan representasi gay melalui idiom penggunaan warna, video klip ini mengandung unsur budaya berupa pengkritikan terhadap budaya tradisional atau, tatanan sosial yang sudah tertanam di benak masyarakat dalam hal ini adalah budaya patriarki. Sosok MNEK yang menyerupai seorang raja yang dalam budaya patriarki raja digambarkan sebagain tokoh yang gagah, namun dalam video ini digambarkan sebagai tokoh yang feminim. Selain itu kritikan terhadap patriarki juga digambarkan oleh sosok Hailee yang menggunakan mahkota disebelah MNEK yang menyatakan bahwa seorang wanita juga mampu untuk menduduki tahtah tertinggi.

Selain itu, lagu ini memberikan kritik mengenai hubungan heteroseksual merupakan hubungan yang biasa, membosankan dan monoton, yang jika digambarkan secara tersirat melalui lirik lagu ini dengan idiom warna hitam dan putih saja scene awal video klip. Sedangkan hubungan homoseksual merupakan hubungan yang lebih berwarna seperti pelangi yang ditandai dengan penggunaan banyak warna yang jauh berbeda pada scene-scene yang menggambarkan kaum gay. Selain dari scene dan visual yang ditampilkan dalam video, kritikan juga ditunjukkan melalui lirik lagu tersebut.

Kembali ke awal MNEK membuat lagu ini dengan alasan untuk menunjukkan jati dirinya yang sesuangguhnya, seperti yang dimuat dalam pemberitaan di www.bbc.com MNEK ingin memberikan kesempatan bagi orang-orang untuk mengenal dirinya secara keseluruhan. Artikel dengan judul "I want people to know it's Ok to be black and gay" yang dimuat adalah hasil wawancaranya dengan MNEK terkait lagu Color pada album barunya. 


\section{Ucapan Terima Kasih}

Penulis mengucapkan terima kasih kepada pihak-pihak yang telah membantu dalam proses penelitian hingga dipublikasikan, terutama kepada narasumber yang telah bersedia meluangkan waktu untuk kerjasamanya selama proses penelitian ini berlangsung.

\section{Daftar Pustaka}

Christany, J. (2013). Realitas Lesbian, Gay, Biseksual dan Transgender (LGBT) Dalam Majalah. Jurnal Komunikasi, 06,3.25.

Go, F. P. (2013). Representasi Stereotipe Perempuan dalam Film BRAVE. Jurnal Komunikasi, 01,2. 2.

McQuail, D. (2012). Teori Komunikasi Massa McQuail. Jakarta: Salemba Humanika.

Moelong, L. J. (2013). Metode Penelitian Kuantitatif. Bandung: PT. Remaja Rosda Karya.

Mukarom, Z. (2008). Perempuan dan Politik, Studi Komunikasi Politik tentang Keterwakilan Perempuan di Legislatif. Jurnal Komunikasi Politik, 9,2. 258.

Mulyana, D. (2007). Ilmu Komunikasi Suatu Pengantar. Bandung: PT. Remaja Rosda Karya.

Nugroho, E. (2008). Pengenalan Teori Warna. Yogyakarta: Andi Publisher.

Omara, A. (2004). Perempuan, Budaya Patriarki dan Representasi. Mimbar Hukum, 149.

Paramita, S., \& Chaniago, A. Z. (2017). Representasi Identitas Tomboy Pada Film Inside Out. Jurnal Komunikasi, 11,02 474-479.

Ruslan, R. (2008). Manajemen Public Relation dan Media Komunikasi. Jakarta: PT. Raja Grafindo Persada.

Turiman. (2015). Metode Semiotika Hukum Jaques Derrida Membongkar Gambar Lambang Negara Indonesia. Jurnal Hukum, 310-317. 